\title{
Herdeiros de um modo de vida: \\ midiativismo contra a ameaça de mineração no rio Camaquã ${ }^{1}$
}

\author{
Heirs of a Way of Life: \\ mediactivism against the mining threat on the Camaquã river
}

Claudia Herte de Moraes ${ }^{2}$, Eliege Maria Fante ${ }^{3}$

Resumo: Este artigo faz um mapeamento das publicações, na rede social Facebook, de moradores midiativistas ambientais sobre o projeto de mineração no Rio Camaquã (RS). O objetivo é refletir sobre as postagens de resistência do midiativismo ambiental na sua interconexão com a luta pelo direito ao ambiente saudável. Na revisão teórica, a partir de um histórico do lugar, verifica-se que as populações atingidas por projetos do desenvolvimentismo buscam formas de resistência ao longo dos anos, com isso fortalecendo ações coletivas. $\mathrm{Na}$ análise, apresenta a resistência das comunidades como única forma de sobreviverem diante das agressões da mineração. Entra em cena o midiativismo ambiental, a partir da sua potencialização com a rede social Facebook. Nas considerações finais, indica que a comunicação para a cidadania é certamente objeto da comunicação pela cidadania, na medida em que a análise de um jornal de referência e da agência de notícias do governo do Estado, nos últimos cinco anos, evidencia a limitada atenção ao conflito e é condicionada à justificativa econômica do empreendimento.

Palavras-chave: Midiativismo; Cartografia; Redes sociais; Rio Camaquã; Jornalismo.

\begin{abstract}
This article tracks publications on Facebook social network posted by environmental mediactivists residents about the mining project in Rio Camaquã (RS). The objective is to ponder on the resistance posts of environmental mediactivism and how they interconnect with the fight for the right to a healthy environment. In the theoretical review, based on the history of the place, it verifies that the populations affected by developmentalism projects seek forms of resistance over the years, thereby strengthening collective actions. In

\footnotetext{
${ }^{1}$ Trabalho realizado no âmbito do Grupo de Pesquisa Jornalismo Ambiental (CNPq/UFRGS), PPGCOM/UFRGS, e com bolsa de doutoramento CAPES.

2 Jornalista, doutora em Comunicação e Informação, Professora no Departamento de Ciências da Comunicação da UFSM, campus Frederico Westphalen.

${ }^{3}$ Doutoranda em Comunicação e Informação pelo PPGCOM/UFRGS. Integrante do Grupo de Pesquisa Jornalismo Ambiental (CNPq/UFRGS). É filiada ao Núcleo de Ecojornalistas do Rio Grande do Sul (NEJ-RS).
} 
the analysis, it presents the resistance of the communities as the only way of surviving in the face of the aggressions of the mining. Environmental mediactivism comes on the scene, from its empowerment with the Facebook social network. In the final considerations, it indicates that communication for citizenship is certainly the object of communication by citizenship, since the analysis of a reference newspaper and the state government news agency in the last five years shows limited attention to conflict, that is conditioned by the economic justification of the enterprise, a reality that contrasts with the occurrence of two environmental crimes against rivers in Brazil in this period (Bento Rodrigues/MG, 2015; Brumadinho/MG, 2019).

Keywords: Mediactivism; Cartography; Social networks; Rio Camaquã; Journalism.

\section{Introdução}

O projeto Caçapava do Sul foi apresentado pela Votorantim Metais ao governo do Rio Grande do Sul em 2016. Consiste numa parceria de joint venture entre Nexa Resources e Mineração Iamgold Brasil para a mineração de zinco, chumbo e cobre. Essa iniciativa é apresentada como solução para o desenvolvimento da metade sul do estado, comumente criticada pelo suposto atraso e pobreza econômica; as comunidades reuniram os diversos setores sociais nos quais atuam para dar o contraponto à política estadual que está sendo imposta à região. Assim surgiu o protagonismo midiativista ambiental do grupo União pela Preservação do Rio Camaquã (UPP - Rio Camaquã) através da página no Facebook Rio Camaquã - União pela Preservação. Outras páginas na mesma rede social passaram a curtir e a compartilhar as postagens que mostram o território ocupado historicamente (o oposto do "vazio demográfico" do senso comum) e a viabilidade econômica e ambiental da principal atividade, a pecuária, da qual outras derivam e geram empregos e renda na região.

Motivadas por esta experiência midiativista, nos propomos, neste trabalho, a refletir sobre uma comunicação democrática, que contemple os direitos humanos, e aqui frisamos o direito ao meio ambiente saudável, que é uma das reivindicações do movimento pela preservação do Rio Camaquã. Por isso, buscamos entender de que forma este movimento e seus apoiadores se articulam para trazer visibilidade às suas pautas. As questões norteadoras desta pesquisa são: Como a construção da cidadania e o direito ao ambiente saudável são mobilizados nas postagens? Quais memórias do lugar e de seus modos de vida estão em disputa sobre o uso do rio Camaquã na região?

Além das publicações da página no Facebook Rio Camaquã - União pela Preservação, bem como outras páginas de apoiadores, trouxemos para a nossa análise a problematização da 
abordagem governamental e de um jornal de referência do Rio Grande do Sul sobre o referido projeto de mineração. A comparação se justifica, já que o governo estadual é o responsável pela execução de políticas públicas de desenvolvimento em consonância com os preceitos, instituídos pelos códigos federal e estadual, de direito à vida e ao ambiente saudável. Por isso, faremos um tensionamento das informações (governamental, do jornalismo hegemônico e da comunidade local) a partir da cartografia das notícias e publicações veiculadas, seja pela agência de notícias do governo estadual, pelo jornal Correio do Povo ou pelas postagens na página do Facebook Rio Camaquã - União pela Preservação e outras apoiadoras.

\title{
2. Cartografia como coletivo de forças
}

Este estudo apresenta um mapeamento, de objetivo cartográfico, das informações compartilhadas, tanto pela agência de notícias governamental quanto pelo jornalismo de referência e especialmente por meio de redes sociais de comunidades mobilizadas em favor de seu modo de vida e do direito à cidadania ambiental. A cartografia, nas Ciências Sociais, é entendida como "estratégia de análise crítica e ação política, olhar crítico que acompanha e descreve relações, trajetórias, formações rizomáticas, a composição de dispositivos, apontando linhas de fuga, ruptura e resistência” (PRADO FILHO; TETI, 2013, p. 45).

Para Passos et al. (2015), o sentido da cartografia é "acompanhamento de percursos, implicação em processos de produção, conexão de redes ou rizomas”, tendo-se em conta, portanto, que a cartografia é um princípio do rizoma "inteiramente voltado para uma experimentação ancorada no real”, de acordo com Deleuze e Guattari (1995, p. 21 apud PASSOS et al., 2015).

\begin{abstract}
A realidade cartografada se apresenta como mapa móvel, de tal maneira que tudo aquilo que tem aparência de "o mesmo" não passa de um concentrado de significação, de saber e de poder, que pode por vezes ter a pretensão ilegítima de ser centro de organização do rizoma. Entretanto, o rizoma não tem centro (PASSOS et al., 2015, p. 10).
\end{abstract}

Entre tantas abordagens possíveis, conforme a natureza dos objetos das pesquisas, adotamos a ideia da cartografia como construção de um coletivo de forças, a partir de um duplo movimento, pista indicada por Escóssia e Tedesco (2015, p. 92-93): de um lado, como processo de conhecimento que não apenas descreve e/ou classifica os objetos de estudo, “[...] mas principalmente preocupa-se em traçar [...] seu processo constante de produção"; de 
outro, a cartografia se coloca como prática de intervenção, pois “[...] acessar o plano das forças é já habitá-lo [...]”, sendo um terreno de participação e intervenção em um determinado coletivo de forças, no qual também há transformações. Desta forma, a cartografia é um método para ser experimentado e assumido como uma atitude, no qual a “[...] precisão não é tomada como exatidão, mas como compromisso e interesse, como implicação na realidade, como intervenção" (PASSOS et al., 2015, p. 11).

\section{A "nova" moda da mineração no RS}

Houve um período histórico de mineração no Rio Camaquã (1865-1996) que deixou marcas profundas de contaminação em uma das poucas áreas de remanescentes de fauna e flora características do bioma Pampa. O antes e o depois dessa fase tiveram o predomínio das práticas pecuárias conservacionistas, uma vez que os animais pastadores (bovinos, equinos, ovinos, caprinos) mantêm as características da vegetação campestre, gramínea e arbustiva. A fauna tem como expressões, dentre outras, as aves de diversos portes convivendo harmoniosamente com a exploração econômica da pecuária.

"Experiências inovadoras de uso sustentável dos campos sulinos" estão relatadas em publicação da Rede de Pesquisa Científica Campos Sulinos (VÉLEZ-MARTIN et al. apud PILLAR; LANGE, 2015, p. 155). Um caso emblemático descrito é o do Seu Decinho e de sua irmã Irene Pereira Franco, que administram 170 hectares na localidade de Guaritas em Caçapava do Sul (RS), lugar de belíssimas imagens reconhecidas em diversas produções cinematográficas, de turismo cultural e ecológico, ensino e pesquisa sobre a biodiversidade. Há mais de 50 anos eles se dedicam a criação de ovelhas, o que lhes rendeu, há mais de 30 anos, a qualificação para o registro de reprodutores da raça Ideal. Acreditam na ovinocultura como a principal atividade em campo nativo, ou seja, em harmonia com a natureza e a vida existente do lugar. O tempo do Pampa é outro, dizem os irmãos, tem a ver com o clima frio, com a vegetação rasteira, com a fauna nativa, um saber de convivência harmoniosa acumulado há gerações. As terras que administram, herdaram da bisavó; cresceram ali nas Guaritas, conhecem as 40 espécies de cacto até agora catalogadas, assim como as espécies endêmicas. "Tivemos anos difíceis, mas acreditamos e continuamos porque os anos bons se sucedem aos ruins, e assim a pecuária vai se valorizando quando aliada ao campo nativo", disse Seu Decinho em relação às "modas econômicas" que os governos, ciclicamente, inventam para a região - ora a sojicultura, ora a monocultura de eucaliptos ou a mineração (VÉLEZ-MARTIN et al. apud PILLAR; LANGE, 2015, p. 162). 
Os irmãos participam, junto de outras centenas de famílias, da experiência de desenvolvimento territorial Alto Camaquã ${ }^{4}$, iniciada em 2005 pela Empresa Brasileira de Pesquisa Agropecuária - Embrapa Pecuária Sul, a qual integra pecuaristas familiares de oito municípios naquela região. Em importante evento ${ }^{5}$, o pesquisador que orienta os trabalhos, Marcos Borba, explicou que esta experiência foi:

construída a partir da valorização dos recursos tangíveis (recursos naturais, pecuária sobre campo nativo, produtos tradicionais) e intangíveis (cultura, representações simbólicas, história etc.), próprias de uma região que permaneceu à margem dos modelos de desenvolvimento aplicados historicamente ao mundo rural brasileiro.

O objetivo final de todo este trabalho é montar uma indústria própria para controlar a cadeia da carne ovina, desde a produção até a distribuição. Por isso, a página no Facebook desta iniciativa ${ }^{6}$ também se manifestou contrária ao projeto de mineração. Na sequência, apresentamos o texto compartilhado em uma das postagens:

É um projeto que trabalha há mais de dez anos defendendo a sustentabilidade de um território, promovendo produtos únicos de um lugar único (cordeiro, borrego, ovelha de descarte, lã, mel, gastronomia, turismo, artesanato...). Através do associativismo e do cooperativismo tentamos conseguir o apoio de produtores, instituições, prefeituras... para dar uma resposta através de produtos ao consumidor exigente, que procura produtos produzidos de forma sustentável, que não agridam a natureza, produtores que utilizem a natureza como aliada.

Temos parceiros inseparáveis como a Embrapa Bagé, Ematers de alguns municípios, sindicatos (em especial o sindicato dos trabalhadores rurais de Pinheiro Machado), alguns prefeitos... precisávamos de mais prefeituras parceiras dentro de nossos 8 municípios (Bagé, Pinheiro Machado, Piratini, Canguçu, Encruzilhada do Sul, Santana da Boa Vista, Caçapava do Sul e Lavras do Sul). Lutamos contra a mineração de metais pesados porque ela é contra esse desenvolvimento sustentável, QUEM IRIA COMPRAR PRODUTOS PARA SE ALIMENTAR, TENDO COMO VIZINHO UMA MINERADORA DE CHUMBO POR EXEMPLO, ONDE A EXTRAÇÃO FICA A CÉU ABERTO, PROVOCANDO CHUVA ÁCIDA, QUEM ACHA SEGURO TER UMA BARRAGEM DE RESÍDUOS NA CABECEIRA DO RIO CAMAQUÃ?

\footnotetext{
${ }^{4}$ Disponível em: https://pt-br.facebook.com/territorioaltocamaqua/. Acesso em: jun. 2019.

5 Trata-se do Seminário Internacional "Inovação Social em Políticas Públicas”, realizado em Brasília (DF), em 2018. Disponível em: https://bit.ly/2LJlwcP. Acesso em: jun. 2019.

${ }^{6}$ A página "Alto Camaquã" foi criada em 11 de abril de 2013 e tem 2.098 curtidas. Disponível em: https://www.facebook.com/territorioaltocamaqua/. Acesso em: jul. 2019.
} 
Não somos contra o progresso, apenas queremos segurança ambiental no RS.

O risco de ter como vizinha uma mineradora de chumbo e, acrescentamos, zinco e cobre, não foi apenas força de expressão descrita acima na reprodução do post da experiência Alto Camaquã. O projeto Caçapava do Sul, se confirmado, se instalará numa área de 388 hectares a nove quilômetros das Guaritas, propriedade do Seu Decinho e da Dona Irene, no município de Caçapava do Sul. Santana da Boa Vista, Bagé e Pinheiro Machado também integram o projeto. O discurso do "moderno" está presente na fala do empreendedor, que garante a não utilização de barragem para rejeitos ou água. A técnica a ser empregada consiste no empilhamento a seco dos rejeitos. Mesmo supondo que esta técnica funcione, em um empreendimento minerário há várias formas de poluição e degradação, como os malefícios do material particulado enfrentado pelas comunidades já atingidas e tantos outros a serem repensados.

Conforme a nossa análise neste trabalho, o governador Eduardo Leite (PSDB) e a empresa Nexa Resources deveriam considerar a posição dos moradores daquele território. Eles reclamam da falta de informações sobre o projeto e de escuta, principalmente por parte do governo do Estado, desde gestões passadas. Uma publicação ${ }^{7}$ do setor minerário revela que o projeto se encontra na fase de busca de licença prévia no órgão licenciador, a Fundação Estadual de Proteção Ambiental Henrique Luiz Roessler (Fepam), a qual solicitou a realização de estudos complementares à empresa.

\section{Cidadania e justiça ambiental}

A parca difusão de informações por parte do governo do Estado e a diminuta escuta da posição contrária ao projeto de mineração (mantida pelos midiativistas que defendem a preservação do Rio Camaquã) evidenciam a disputa pelo direito à Comunicação e ao ambiente saudável. Ambos os direitos se encontram na construção da cidadania ambiental, uma vez que não é possível que a sociedade decida sobre seu futuro ambiental sem acesso às informações em quantidade e qualidade suficientes para que a compreensão deste tema seja realizada em bases justas.

A própria Constituição Federal do Brasil, no Artigo 225, determina que "Todos têm direito ao meio ambiente ecologicamente equilibrado, bem de uso comum do povo e essencial à sadia qualidade de vida, impondo-se ao Poder Público e à coletividade o dever de defendê-

\footnotetext{
${ }^{7}$ Disponível em: https://bit.ly/2MkS6Bc. Acesso em: jul. 2019.
} 
lo e preservá-lo para as presentes e futuras gerações." Como se já não fosse diretriz suficiente para o poder público estadual, leia-se o governo, e também à coletividade, no caso a própria empresa, a Constituição do Estado do Rio Grande do Sul (RS), corrobora no Artigo 250: “O meio ambiente é bem de uso comum do povo, e a manutenção de seu equilíbrio é essencial à sadia qualidade de vida.”. Importa ainda destacar o Artigo 251:

Todos têm direito ao meio ambiente ecologicamente equilibrado, impondose ao Poder Público e à coletividade o dever de defendê-lo, preservá-lo e restaurá-lo para as presentes e futuras gerações, cabendo a todos exigir do Poder Público a adoção de medidas nesse sentido.

Em seu parágrafo primeiro, a lei apresenta diversas ações permanentes que o RS deve empreender para "assegurar a efetividade desse direito". Entre elas, destacamos: "VII proteger a flora, a fauna e a paisagem natural, vedadas as práticas que coloquem em risco sua função ecológica e paisagística, provoquem extinção de espécie [...]”. Como vimos desde o início deste trabalho, a atividade econômica que, naquela região em disputa, conserva o ambiente e valoriza a cidadania é a pecuária familiar, com a qual praticantes, universidades e Embrapa desenvolvem parcerias há décadas (VÉLEZ-MARTIN et al. apud PILLAR; LANGE, 2015).

No contexto dos conflitos socioambientais, é imprescindível o debate de ideias e saberes outros, que não apenas aqueles oriundos do espectro econômico, restrito ao quantitativo positivo e exclusivo do ente investidor. Em situações nas quais o direito humano ao ambiente saudável é constantemente ameaçado, visualizamos comunidades que buscam formas de re-existência baseadas em modos de vida tradicionais, ou seja, a partir de heranças socioculturais que marcam ações coletivas. A injustiça ambiental presente nos projetos de desenvolvimento econômico é a base para os conflitos ambientais, na medida em que " [...] empreendimentos, privados e públicos não estão chegando num território que seria ao mesmo tempo vazio de gente e "vazio" de natureza, como se fosse uma terra arrasada, um imenso terreno baldio disponível para qualquer coisa" (LEROY, 2014, p. 4). Desta forma, afirma Leroy (2014), as populações que habitam o território "têm uma história de vida, de sobrevivência e de reprodução humana e econômica e que têm propostas e projetos para elas e para a região. Não aceitam mais que lhes sejam impostos a força projetos destruidores do seu futuro" (idem).

A ambientalização dos conflitos sociais fez surgir a concepção de um movimento de re-existência: “[...] um modo de vida e de produção, modos diferenciados de sentir, de pensar 
e de agir”. (PORTO-GONÇALVES, 2001 apud TEISSERENC, 2010, p. 160). Teisserenc pontua, então, que a produção de identidades coletivas e de espaços ecológicos "faz emergir um novo território, apresentando-se ao mesmo tempo como sendo simbólico, cultural e político, tornando-se o desafio de uma nova forma de apreensão do mundo, de uma nova maneira de pensar" (ibid., p. 161). Desta forma, um conflito social "não é uma manifestação espontânea, é reflexo da condição social e do despertar para o mundo da política na vida cotidiana" (SANTANA JÚNIOR; ALVES, 2018, p. 267).

Ainda, ao pensarmos sobre os direitos da justiça ambiental, sobressai também o sentido de humanização do território:

\footnotetext{
Humanizar o território significa reconectar esse território, a produção, a vida, a população com a sua base material e natural na sua imensa diversidade socioambiental. É assim que a práxis da justiça ambiental, enquanto luta de populações para que sejam respeitados e/ou restabelecidos o seu laço e a sua integração com o seu meio ambiente, contribui para que sejam construídos outros projetos de futuro, numa outra relação do ser humano com a natureza (LEROY, 2014, p. 6).
}

Diante da ameaça da apropriação do Rio Camaquã para a mineração, com o aval do governo do Estado, os moradores do lugar se percebem impedidos de continuar as atividades relacionadas ao modo de vida herdado. Portanto, cabe o conceito de conflito ambiental em Acselrad (2005, p. 26), que dispõe sobre a disputa em torno dos " [...] modos diferenciados de apropriação, uso e significação do território [...]". Acselrad diz ainda que a noção de justiça ambiental se manifesta como resultado de uma "[...] apropriação singular da temática do meio ambiente por dinâmicas sociopolíticas tradicionalmente envolvidas com a construção da justiça social.” Neste sentido, no embate social de disputa pelos futuros, a questão ambiental "se mostra cada vez mais central e vista crescentemente como entrelaçada às tradicionais questões sociais do emprego e da renda" (ACSERALD, 2010, p. 108).

\section{Midiativismo ambiental na cultura midiática}

A análise empreendida neste artigo leva em conta as modificações sociotécnicas que permitem aos cidadãos manifestar de forma direta suas opiniões e informações, criando-se, assim, um espaço de ampliação da participação na comunicação em rede. Com isso, entendemos que há modificações e reconfigurações na relação entre jornalismo e sociedade, bem como entre os poderes exercidos em nome da população, especialmente entre os 
governantes e a comunidades diretamente afetadas pelas políticas públicas. As relações de poder são, portanto, tensionadas, bem como evidenciam-se alterações "[...] nos fluxos informacionais e nos movimentos sociais - que se reinventam, são potencializados pela Cibercultura, recondicionam pautas tradicionais e mobilizam novas ações em rede" (ALMEIDA, 2015, p. 12).

Miguel e Biroli (2010) indicam que a constituição de redes possibilita a produção de informação a partir de novas perspectivas, de grupos sociais que antes estavam silenciados. Desta forma, a cidadania comunicativa se une à cidadania ambiental, quando apontamos as potencialidades do midiativismo ambiental. O midiativismo é entendido como uma forma de exercer a comunicação aliada aos movimentos sociais, com forte atuação em redes sociais e uso das tecnologias digitais, "com objetivo de construir uma narrativa própria e diferenciada em relação àquela da comunicação hegemônica” (MORAES; FANTE, 2018, p. 339).

Ainda em relação ao midiativismo, cabe salientar que sua gênese está na forma de resistência aos meios de comunicação de massa. Porém, como salienta Maciel (2012, p. 30), “a resistência à cultura da mídia implica, na maioria das vezes, uma negação ou oposição a elementos mais gerais da sociedade capitalista em si, mesmo que confira grande peso relativamente às produções, imposições ou apropriações dos instrumentos tecnológicos de comunicação". Desta forma, o midiativismo encontra-se dentro da cultura midiática e dos processos de midiatização em geral, embora se posicione de forma crítica às formas de comunicação centralizadas que dão suporte ao status quo. Com isso, importa refletir sobre as possibilidades do midiativismo, tendo em vista o conceito de midiatização em Gomes (2016, p. 18), que postula a configuração de um ambiente midiatizado no qual os meios não são apenas instrumentos de relações pessoais, "mas fazem parte da autocompreensão social e individual".

Não obstante as experiências midiativistas possam se constituir em curtos espaços de tempo, em que possamos observá-las para mapeamento, concordamos com Maciel (2012, p. 10) ao estimar que o entendimento do midiativismo, por estar imbricado nas mídias, se encontra nos seus efeitos, "principalmente a partir de uma disputa também no campo semântico, na produção de teorias e significados que justifiquem o próprio uso das mídias para a construção de uma outra sociedade".

O debate público sobre "projetos de desenvolvimento" é geralmente contaminado pela visão socioambiental das elites, que mantém estreita relação com os meios de comunicação tradicionais e corporativos. Desta forma, o midiativismo ambiental é essencial para a construção da justiça ambiental. De acordo com Mazzarino (2012), a ampliação do debate 
sobre os temas socioambientais "tem a força de poder desencadear a criação de capital social pela natureza da sua problemática” (p. 21). Na avaliação da autora, entre outros efeitos, há geração de partilha em relação aos valores da cidadania ambiental, a percepção da interdependência ecológica, a formação de laços de pertencimento e a criação de objetivos comuns para a melhoria das condições socioambientais.

Em estudo sobre o midiativismo ambiental em Porto Alegre, capital do Rio Grande do Sul, foram mapeadas três situações desta prática: por entidades ambientalistas; por ambientalistas individualmente em blogs ou redes sociais; e por comunicadores e outros profissionais apoiadores do movimento ambientalista (MORAES; FANTE, 2018). Neste trabalho, temos como foco o midiativismo contra o projeto de mineração do Rio Camaquã e buscamos desenvolver essa cartografia, incluindo a noção de que as redes de midiativistas são formadas também por pessoas que promovem a compreensão do modo de funcionamento do lugar, ecológica e economicamente, com uma mobilização cidadã ao difundir as suas informações em páginas de rede social. O perfil geral deste movimento se estrutura no posicionamento de pessoas nativas daquele território em relação às questões socioambientais com o uso de postagens em rede social que, em alguma medida, se relacionam aos movimentos ambientalistas e/ou entidades e Organizações Não Governamentais (ONGs).

O midiativismo ambiental é conceituado como "[...] a complexa relação que se forma entre as causas ambientais, seus defensores e as suas formas de midiatização" (MORAES; FANTE, 2018, p. 352). Com a observação das lutas ambientais sul-rio-grandenses, especialmente em nosso momento histórico contemporâneo, atualizamos este conceito substituindo "defensores" por "mobilizadores", em função de que os ambientalistas têm expressado que as ações de proteção ao meio ambiente e à natureza, bem como as reações às ameaças, devem se dar por ações impulsionadoras, envolvedoras, "mobilizadoras" para a construção das possibilidades necessárias a um outro modelo de desenvolvimento para além dos limites impostos pelo capital.

Além disso, destacamos que, por ser uma região do interior gaúcho, há carência de informações midiatizadas daquela sociedade, principalmente pelo papel exercido por veículos tradicionais que, via de regra, se ocupam de notícias sobre temas diretamente relativos ao entorno dos poderes e de fontes oficiais, e focam a cobertura nos grandes centros econômicos e capitais. Desta forma, acrescentamos que o midiativismo ambiental se constrói de inúmeras formas, tanto em nível institucional, por meio de ONGs e entidades já consolidadas do movimento ambiental, quanto pelo cidadão "comum", aquela pessoa que vivencia de perto o impacto dos projetos de mineração. Ademais, a pista para identificar o midiativismo está 
também em seus conteúdos, uma vez que "[...] midiativistas buscam a participação do público nos acontecimentos, os quais eles acreditam estejam invisibilizados ou sem a atenção merecida por parte do público em geral" (MORAES; FANTE, 2019, p. 343).

\section{Informação oficial e de massa}

Buscamos a abordagem do projeto Caçapava do Sul na Agência de Notícias ${ }^{8}$ on-line do Governo do RS com as palavras-chave "Minas do Camaquã" e "Rio Camaquã". Entre 1" de junho de 2015 e $1^{\circ}$ de junho de 2019 , apenas três notícias relacionadas foram encontradas. A primeira é sobre a interdição de duas barragens, sendo uma justamente na área onde a mineração foi interrompida em 1996, que se localiza a poucos quilômetros abaixo da propriedade de Seu Decinho e Dona Irene. O comunicado ${ }^{9}$ diz que em caso de colapso da estrutura "não há risco de inundação". Em notícia de $2016^{10}$, afirmam que a produção (leia-se extração da riqueza e consequente abandono de área degradada) deve ser de 36 mil toneladas de chumbo contido, 16 mil toneladas de zinco e cinco mil toneladas de cobre contido, ao ano. A finalidade é a exportação. Como se fosse o suficiente para as comunidades aderirem ao projeto, informam o "investimento previsto de $\mathrm{R} \$ 322$ milhões" e uma "expectativa” de gerar 450 empregos diretos na fase de operação. Mesmo que se apresentassem ofertas de capacitação para os gaúchos campeiros atuarem nas minas, isso pouco sentido teria às comunidades descendentes de colonizadores espanhóis e portugueses adaptados à lida rural e pecuária. Finalmente, em vistoria técnica para conferir a viabilidade do projeto em Minas do Camaquã ${ }^{11}$, a então secretária do Ambiente e Desenvolvimento Sustentável, Ana Pellini, exaltou a exploração iniciada pela Companhia Brasileira de Cobre em 1942, que, segundo ela, teria deixado "um local turístico de belezas exuberantes e naturais". Como a barragem de rejeitos deixada para trás e interditada conforme a primeira notícia desta amostra.

\footnotetext{
${ }^{8}$ Disponível em: https://estado.rs.gov.br/agencia-de-noticias. Acesso em: jun. 2019.

${ }^{9} \mathrm{O}$ texto intitula-se "Equipe da Defesa Civil realiza visitas técnicas em duas barragens interditadas". Disponível em: https://estado.rs.gov.br/defesa-civil-realiza-visitas-tecnicas-em-barragens-interditadas. Acesso em: 10 abr. 2019.

10 "Votorantim Metais apresenta projeto de mineração em Caçapava do Sul”. Disponível em: https://www.estado.rs.gov.br/votorantim-metais-apresenta-projeto-de-mineracao-em-cacapava-do-sul. Acesso em: 14 jun. 2016.

11 "Mineradora de grande porte prepara instalação em Caçapava do Sul”. Disponível em: https://estado.rs.gov.br/mineradora-de-grande-porte-prepara-instalacao-em-cacapava-do-sul. Acesso em: 5 jun. 2016.
} 
A partir dessas parcas abordagens pelo governo, supúnhamos que um jornal de referência como o Correio do Povo ${ }^{12}$, em nome da busca ao atendimento do interesse público, tivesse cedido mais tempo e páginas de problematização junto às comunidades. Em uma pesquisa no acervo on-line do jornal, no mesmo período, entre $1^{\circ}$ de junho de 2015 e $1^{\circ}$ de junho de 2019, a partir das palavras-chave "Minas do Camaquã" e "Rio Camaquã", encontramos apenas duas notícias. Em $1^{\circ}$ de julho de 2018, no texto "Mineração causa polêmica", contam que a extração da mina deve ser de céu aberto durante 20 anos, numa área de 388 hectares. De que interesse público estamos falando sobre um investimento, de 20 anos, que deixará para trás ecossistemas e suas comunidades devastadas, sendo que antes, durante e depois da experiência de mina na região, a economia campeira gaúcha funcionou e funciona? Marcia Collares, uma das midiativistas resistentes ao projeto, foi ouvida pela reportagem e alertou para a distância da área do projeto em relação às margens do rio Camaquã, de apenas 800 metros. Em entrevista para o jornal, ela disse temer que a produção pecuária à qual se dedica seja impactada pela ameaça que paira sobre a água de grande qualidade. O professor e biólogo da UFRGS Paulo Brack também foi ouvido e classificou como contrassenso a escolha, para essa atividade, de um lugar de espécies endêmicas, ameaçadas de extinção, identificado no Mapa Federal de Áreas Prioritárias para a Conservação da Biodiversidade.

Em 14 de dezembro de 2016, a notícia "Extração preocupa produtores" abordou o receio com o risco de contaminação da Bacia Hidrográfica do Rio Camaquã e a consequente ameaça à continuidade da agropecuária. Destacou a mobilização contrária ao projeto de mineração, por parte de pesquisadores de universidades e centros de pesquisa, prefeitos e representantes das atividades agropecuárias. Entre os dados apresentados, ressaltamos: há de 55 mil estabelecimentos rurais inseridos na bacia; o discurso da megacorporação em nada difere daquele da Vale, responsável pelos dois crimes ambientais provocados em Minas Gerais no período de nossa reflexão (Bento Rodrigues, 2015; Brumadinho, 2019); o projeto seria "um dos mais modernos do país" e não utilizaria barragem de rejeitos, nem destinaria resíduos ao rio Camaquã.

\footnotetext{
${ }^{12}$ Correio do Povo (1895-) pertenceu ao Grupo Caldas até 1984, depois ficou sob a direção de Bastos Ribeiro até 2007, quando o Grupo Record o assumiu. Segundo informações do próprio jornal, ele ocupa o sétimo lugar no Brasil em circulação e tem a maior abrangência no RS. Disponível em: https://bit.ly/2YxHPYL. Acesso em: jul. 2019.
} 


\section{Midiativismo por herdeiros de um modo de vida}

A “compreensão do modo de funcionamento do lugar, ecológica e economicamente" ficou a cargo da mobilização cidadã das pessoas que difundiram as suas informações em páginas de rede social. Evidenciar o que vinha (e continua) sendo ignorado ou omitido pelo órgão de informação governamental, assim como pelo meio impresso de comunicação de massa e de referência do Estado, é um dos objetivos dos midiativistas ambientais que passaremos a apresentar. Em geral, são pessoas de municípios da metade pampiana do Rio Grande do Sul, onde o modo de vida rural vigora, com a pecuária de corte como atividade econômica predominante. $\mathrm{O}$ acesso à internet para difusão de um discurso particular e próprio de manutenção do seu modo de vida para um público amplo e desconhecido, porque não se restringe às fronteiras políticas ou ambientais do território, caracteriza estas pessoas como midiativistas. Nesta atuação, também fazem parte de uma rede de informações, pois em suas páginas no Facebook repetem as publicações uns dos outros, não sendo raros os integrantes que participam de várias páginas em comum.

Iniciaremos a descrição desta rede midiativista ambiental com a página do movimento que consideramos protagonista, o grupo União pela Preservação do Rio Camaquã (UPP - Rio Camaquã). Trata-se da comunidade no Facebook Rio Camaquã - União pela preservação ${ }^{13}$, criada em 26 de setembro de 2016, curtida por 9.115 pessoas e seguida por 9.181 . O objetivo da página é "alertar e mobilizar a população acerca dos danos ambientais que decorrerão da instalação de uma MINERADORA DE CHUMBO às margens do RIO CAMAQUÃ". A seguir, apresentamos algumas postagens destacadas (Figuras 1, 2, 3 e 4), que representam a tônica das publicações, as quais são feitas quase que diariamente.

Na Figura 1, o foco é a valorização das atividades econômicas já consolidadas na região, com a divulgação de evento cultural que expõe o artesanato local. A mostra é organizada e apoiada por várias entidades envolvidas nas questões socioculturais e econômicas do Pampa.

A página reproduz notícia publicada por jornal local (Figura 2), destacando a temática ambiental relacionada aos riscos da mineração, especialmente por ser recente um grande desastre socioambiental, ocorrido em Brumadinho (Minas Gerais). A notícia em questão trata da realização do documentário Dossiê viventes ${ }^{14}$ pelo grupo UPP - Rio Camaquã, sobre a

\footnotetext{
${ }^{13}$ Disponível em: https://bit.ly/2OuoUKD. Acesso em: jun. 2019.

14 Trailer disponível em: https://bit.ly/2K2wSX4. Acesso em: jul. 2019.
} 
mobilização em favor do seu modo de vida campeiro. Conforme foi divulgado, o filme traz mais de quarenta entrevistas, com direção de Tiago Rodrigues e produção executiva de Ingrid Binrfeld. A sinopse explica que "O medo da contaminação, da perda da identidade e da formação cultural do gaúcho, e a ameaça a um projeto de desenvolvimento territorial sustentável e solidário em curso, uniram povos, municípios, cientistas, gestores, políticos e instituições com pluralidade [...]." Ele foi exibido por diversas instituições desde o lançamento ao final de 2018.

Figura 1 - Engajamento para a valorização da atividade econômica local
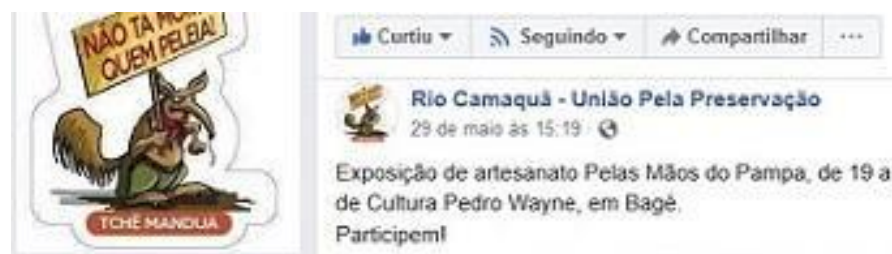

Exposicao de artesanato Pelas Măos đo Pampa, de 19 a 28 de junho, Casa de Cultura Pedro Wayne, en Bage Participem!
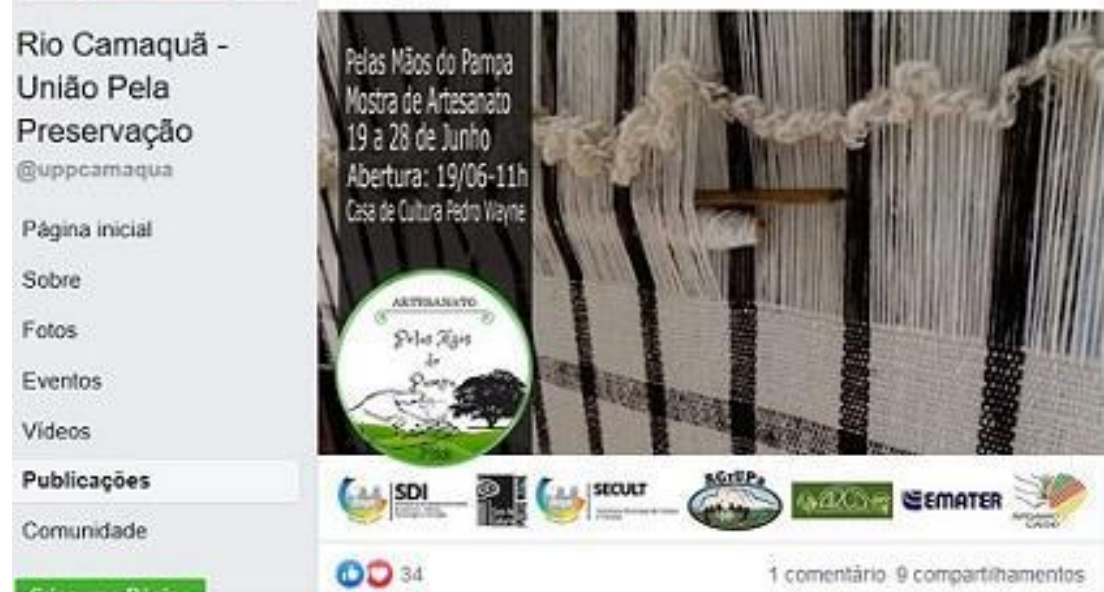

Publicaçōes

Comunidade

Fonte: Reprodução de Rio Camaquã - Unidos Pela Preservação

Figura 2 - Exibição de filme, exposição fotográfica e palestras

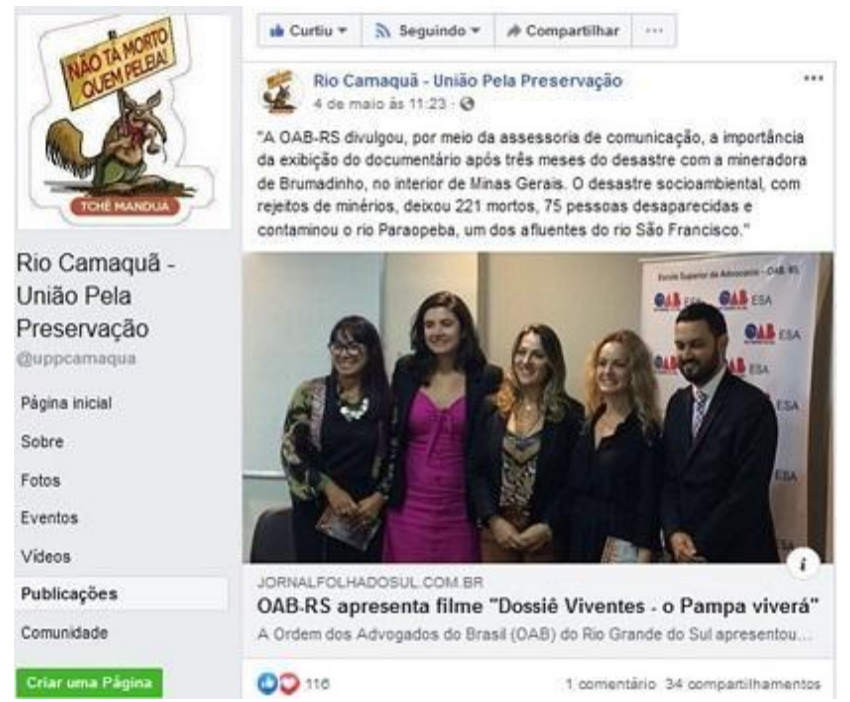

Fonte: Reprodução de Rio Camaquã - Unidos Pela Preservação 
Imagens de fauna e flora endêmicas também povoam o midiativismo da página UPPRio Camaquã. No exemplo da Figura 3, a postagem faz a relação da proteção do bioma Pampa pelos seus antepassados, através da prática econômica da pecuária que conserva a biodiversidade, em contraponto à degradação inevitável que a mineração provoca e à impossibilidade de garantir a restauração dos ecossistemas.

Figura 3 - Difusão da biodiversidade sulina, fauna e flora nativa

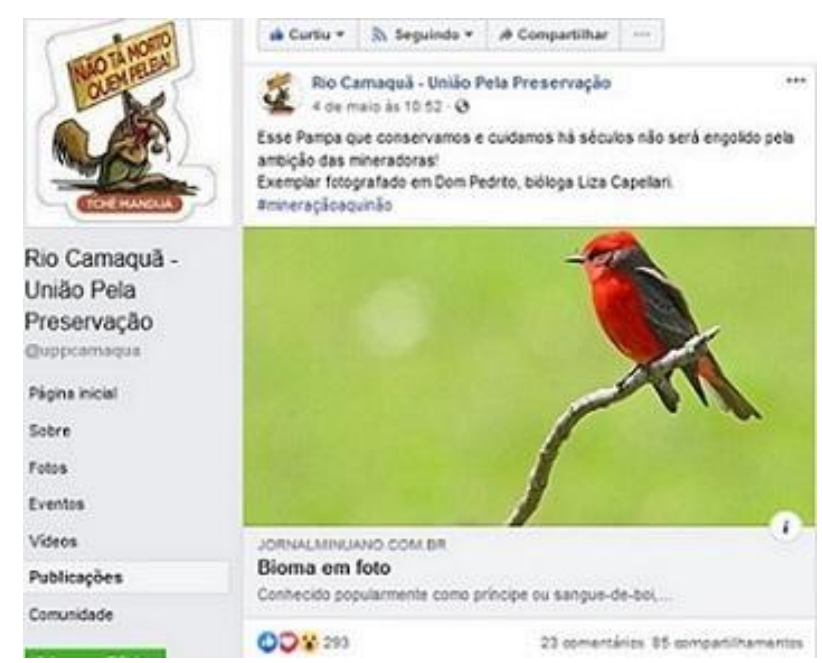

Fonte: Reprodução de Rio Camaquã - Unidos Pela Preservação

Na Figura 4, também encontramos a crítica ao modelo de mineração e à ganância de empresas que geram milhões em lucros sem respeitar as comunidades que estão sob ameaça constante. Há revolta pela situação de Barão de Cocais, localidade de Minas Gerais, onde, sob risco de rompimento da barragem Sul Superior da mina de Congo, mais de 450 moradores tiveram que abandonar suas casas entre fevereiro e julho de $2019^{15}$. Por isso destaca-se: "lutaremos pelo Pampa, lutaremos por nossas casas". O papel midiativista da página é contemplado ao trazer informações de um contexto mais amplo, com isso agregando público e fazendo um alerta para a situação de populações atingidas pela mineração.

A organização da página Rio Camaquã - Unidos Pela Preservação teve também a iniciativa de criar um grupo público no Facebook, em 6 de setembro de 2016, atualmente com 2.870 membros. O post ${ }^{16}$ que destacamos (Figura 5) mostra uma das mais tradicionais atividades econômicas do Pampa; na descrição lemos: "Esse é o desenvolvimento pensado e construído pelos moradores e entidades realmente parceiras; esse é o crescimento que respeita

\footnotetext{
${ }^{15}$ Ver mais em: https://bit.ly/2YgtPDx, Acesso em: jul. 2019.

${ }^{16}$ Disponível em: https://bit.ly/2SHwqjO. Acesso em: jul. 2019.
} 
as potencialidades e vontades de um território. Sabemos o que queremos! \#mineraçãoaquinão".

Figura 4 - Comentários de notícias de jornais locais, regionais e nacionais
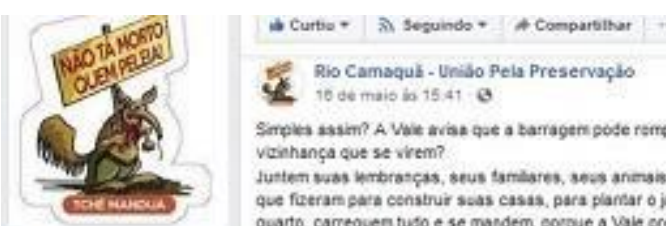
laso t assardo. esse descaso cem a vida dos gutros, essa iresgonsabildade

Uniāo Pela - menosprezo das ertpresss o pencicaimarto dos govemantas. que pernatr ecossisteress intercs, soere cossus aguss:

Preservaçăo

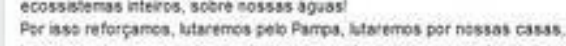

duppeanagus

Pigha ricial vitaremes sor nosses vidos, selo temoo eue for precibo, em lodas os lugares que for brecso a najo acetaremes nata menos do que a vitira"

Sobre

Fotos

Evertos

videos

Doticạ̧̄ò

Comandade
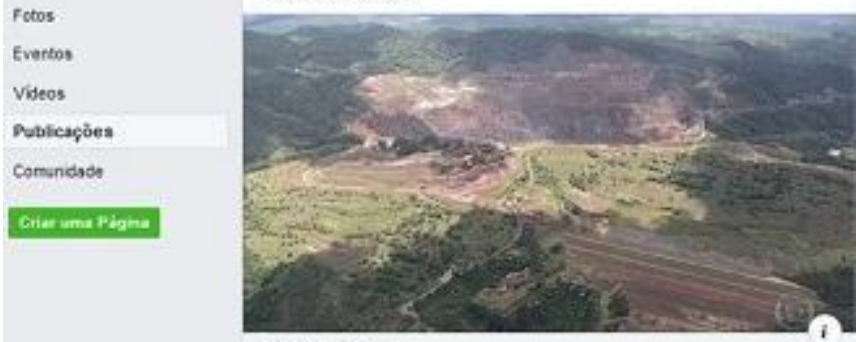

G.06080.004

Vale diz ao MP que talude de mina em Barào de Cocais pode se romper a partir de domingo

Oew $23 s$

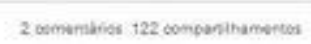

Fonte: Reprodução de Rio Camaquã - Unidos Pela Preservação

Figura 5 - Atividade econômica tradicional

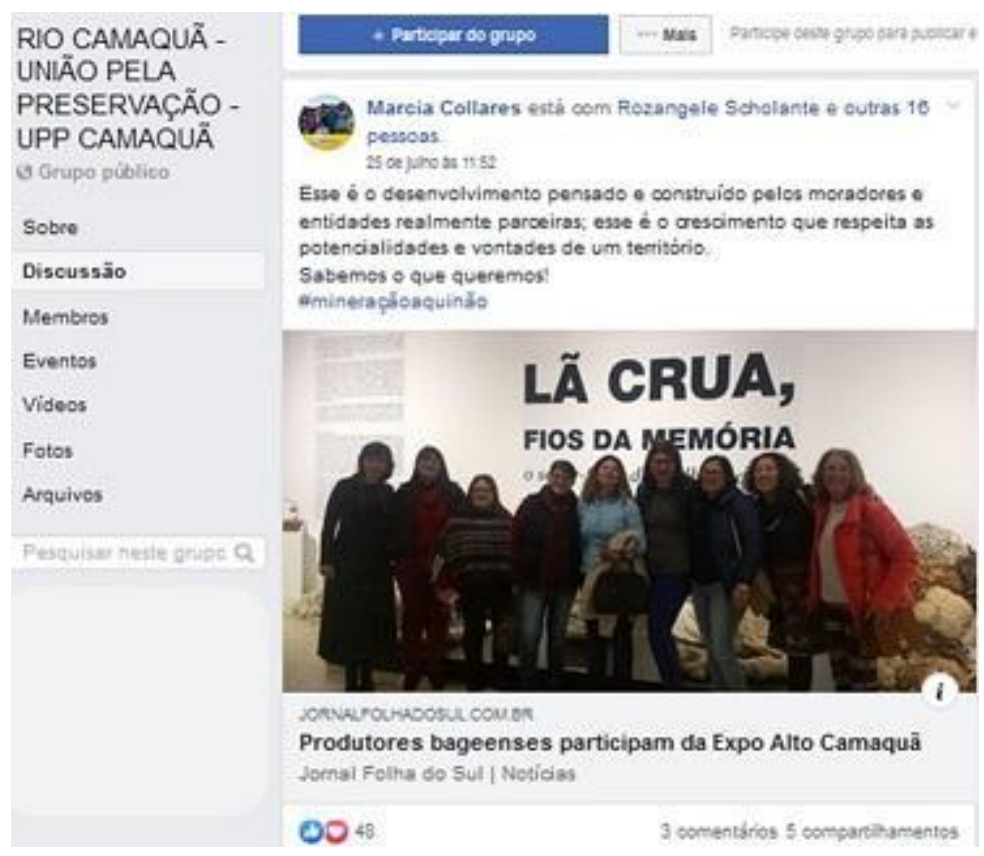

Fonte: Reprodução de Rio Camaquã - Unidos Pela Preservação 
A seleção das páginas constituintes da rede midiativista ambiental sob análise seguiu o critério de proximidade regional, com um número de curtidas superior a mil. Não obstante, antes de finalizar esta parte do trabalho, apresentaremos páginas mais distantes geograficamente, mas identificadas com a mobilização e o midiativismo ambiental.

A página no Facebook do Comitê de Gerenciamento da Bacia Hidrográfica do Rio Camaquã ${ }^{17}$ obteve 1.059 curtidas e 1.078 seguidores. Também compartilha imagens das mobilizações do grupo UPP - Rio Camaquã em defesa do rio e do modo de vida pampiano (Figura 6), caracterizado pela conservação da biodiversidade campestre e da pecuária, bem como das atividades econômicas afins.

Figura 6 - Post do Comitê da Bacia sobre a Expedição no Rio Camaquã

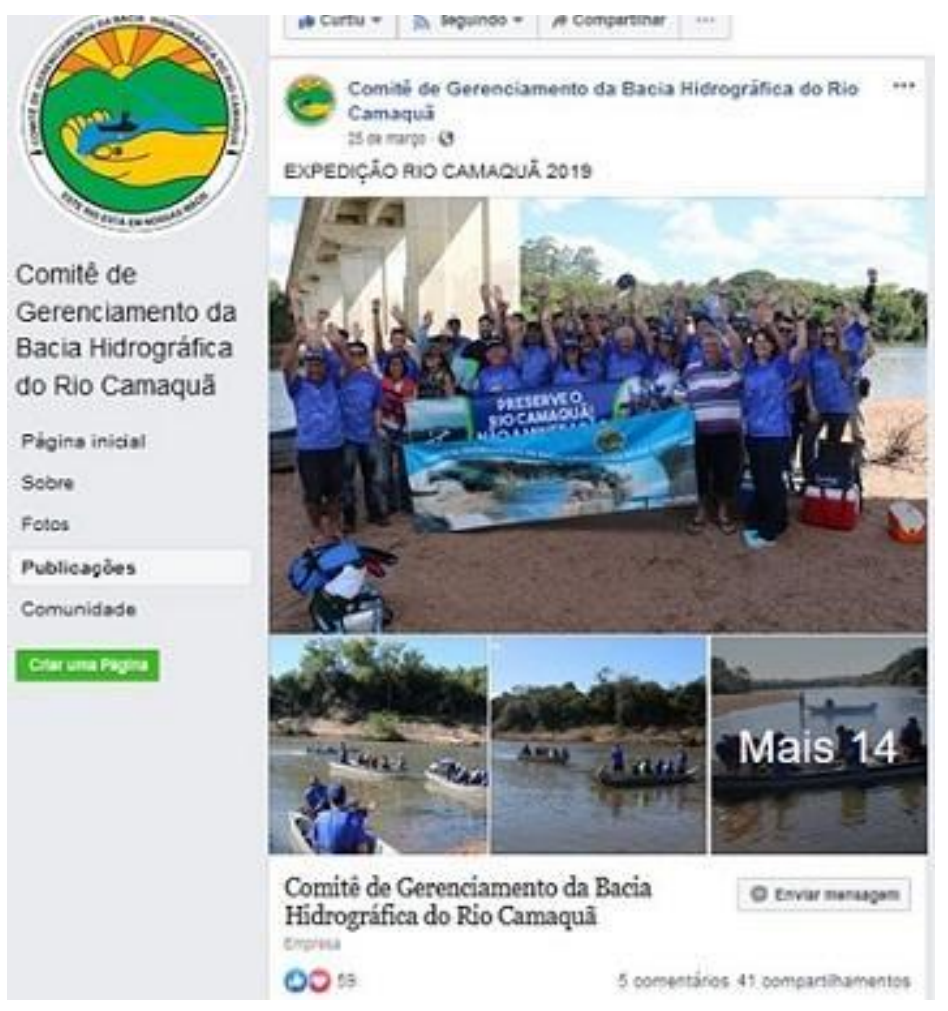

Fonte: Reprodução de Rio Camaquã - Unidos Pela Preservação

A página desta rede de midiativismo ambiental em defesa do Rio Camaquã ${ }^{18}$, que possui o maior número de curtidas (24.359), foi criada em 2013 com o intuito de expor “imagens e parte do contexto social que envolve as Ilhas do rio Camaquã, junto da

\footnotetext{
${ }^{17}$ Segundo divulgações disponíveis, o Comitê foi instituído através do Decreto Estadual 39.638/1999, com base na Lei 10.350/1994, instalado em 13 de abril de 2000 em Camaquã (RS). A finalidade é promover a gestão descentralizada e participativa dos recursos hídricos da bacia do Rio Camaquã. Participam do Comitê representantes de diversas entidades. Disponível em: https://bit.ly/311NALX. Acesso em: jul. 2019.

${ }^{18}$ Disponível em: https://www.facebook.com/Est.RioCqRS/. Acesso em: jul. 2019.
} 
embocadura do rio Camaquã com a Lagoa dos Patos". Vejamos a descrição completa do Estuário do Rio Camaquã por A. Sig. Kath:

Em realce a captura do passado que envolve nossa região, desde sua colonização pelos portugueses. Cada ilha em sua singularidade tem seu espaço por aqui, visitem os muitos álbuns desta página, em cada um, partes, recortes do tempo de toda região do rio Camaquã acrescida pelos inúmeros amigos desta página. Abraço e um rio de felicidades para todos!

A urgência devido à ameaça que representa o projeto de mineração Caçapava do Sul incluiu o apoio manifestado através do compartilhamento (Figura 7), entre outros, reproduzido a seguir:

Figura 7 - Post do Estuário do Rio Camaquã sobre mobilização em aldeia indígena

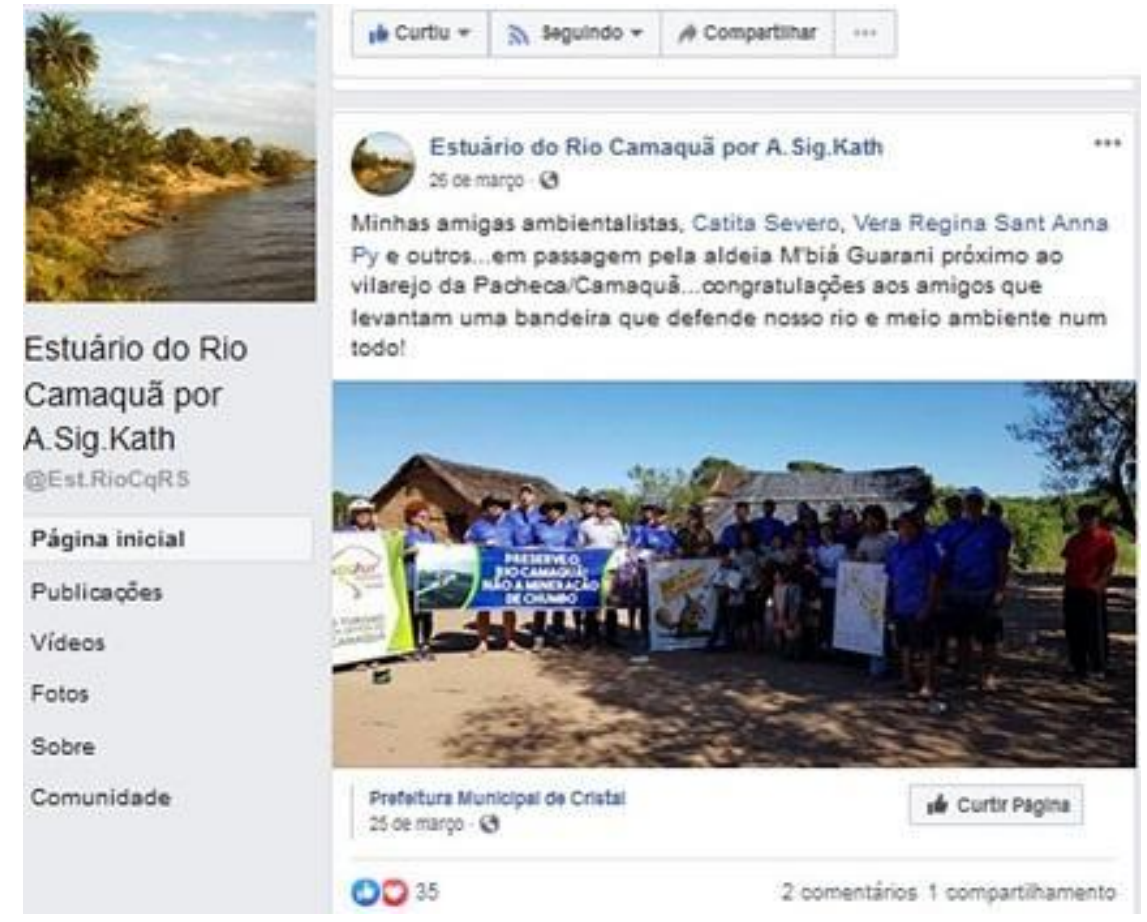

Fonte: Reprodução de Rio Camaquã - Unidos Pela Preservação

Até aqui vimos como se constitui a rede de midiativismo ambiental em defesa do Rio Camaquã e do modo de vida daquele território. Ela é protagonizada pelo grupo UPP - Rio Camaquã, com duas páginas no Facebook, sendo uma da comunidade e outra do grupo público; uma página no Facebook do Comitê de Gerenciamento da Bacia Hidrográfica do Rio Camaquã e uma página no Facebook do Estuário do Rio Camaquã por A. Sig. Kath. Além destas, cujo critério de seleção foi a proximidade regional, identificamos páginas de entidades 
ambientalistas distantes geograficamente, porém com uma prática vigente de midiativismo ambiental. Por exemplo, citamos a Associação Gaúcha de Proteção ao Ambiente Natural (Agapan) ${ }^{19}$, reconhecida internacionalmente. O apoio buscado na capital do estado e prontamente manifestado se evidencia também nos diversos posts na página do Facebook ${ }^{20} \mathrm{da}$ Agapan. Na sequência, reproduzimos a imagem (Figura 8) de um que anuncia a visita a Bagé, numa das localidades a serem atingidas pela mineração, caso o projeto Caçapava do Sul se confirme.

Figura 8 - Agapan visita comunidade ameaçada pelo projeto de mineração

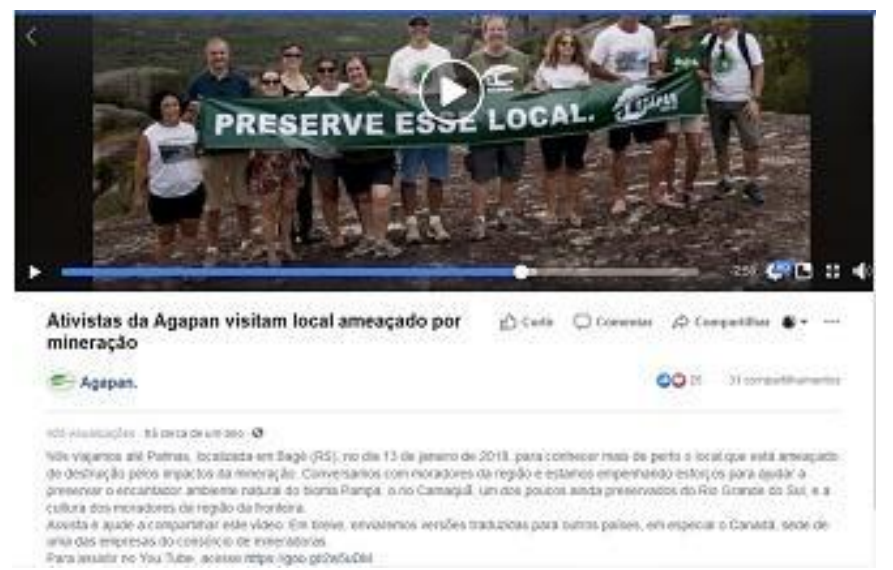

Fonte: Reprodução de Rio Camaquã - Unidos Pela Preservação

O contexto de ameaça da mineração sobre o ambiente e a cultura de diversas regiões no Rio Grande do Sul provocou a união e a organização de um Comitê estadual, de cujo manifesto o grupo UPP-Rio Camaquã também é signatário. Até julho de 2019, mais de 70 entidades assinaram e promoveram mobilizações e debates em todo o estado sobre a questão minerária e os impactos. A página Comitê de Combate à Megamineração no Rio Grande do Sul $^{21}$ foi criada em 10 de junho de 2019, possui 1.860 curtidas e 1.880 seguidores. O manifesto difundido na data de fundação do Comitê (29 de maio de 2019) justifica a mobilização, primeiramente devido à existência de quatro megaprojetos em andamento com o apoio do governo estadual, entre eles o já descrito no início deste trabalho e objeto do midiativismo ambiental do grupo UPP - Camaquã; o projeto Retiro, que visa à extração de titânio da faixa de areia entre o Oceano Atlântico e a Lagoa dos Patos, no município de São

\footnotetext{
${ }^{19}$ A Agapan foi fundada em 1971 por José Lutzenberger, Hilda Zimmermann e tantos outros que motivaram a adesão das gerações seguintes, para continuar a mobilização de acordo com o lema da entidade: "A vida sempre em primeiro lugar”. Informações em: http://www.agapan.org.br/. Acesso em: jul. 2019.

${ }^{20}$ Disponível em: https://www.facebook.com/agapan1971/. Acesso em: jul. 2019.

${ }^{21}$ Disponível em: https://bit.ly/2SOoGwk. Acesso em: jul. 2019.
} 
José do Norte ${ }^{22}$; o projeto Três Estradas, que pretende extrair fosfato em Lavras do $\mathrm{Sul}^{23}$ (município ao lado de Caçapava do Sul), cujo empreendimento inclui uma barragem de rejeitos; o projeto Mina Guaíba, que intenta extrair 166 milhões de toneladas de carvão de uma área de cinco mil hectares nos municípios de Charqueadas e Eldorado do $\mathrm{Sul}^{24}$. A referida área se situa a apenas $16 \mathrm{~km}$ do centro da capital Porto Alegre e também na zona de influência da Área de Proteção Ambiental e Parque Estadual Delta Jacuí, ainda reconhecida como Zona Núcleo da Reserva da Biosfera da Mata Atlântica, um bem tombado como patrimônio cultural e paisagístico do Rio Grande do Sul.

O manifesto justifica a mobilização, a partir, ainda, de mais de 150 outros projetos de mineração em solo sul-rio-grandense. A finalidade de tantos projetos minerários no estado é levá-lo à posição de terceiro maior minerador do país. As demais justificativas do manifesto podem ser encontradas na página do Comitê; na sequência, apresentaremos uma postagem na qual vemos a foto compartilhada de uma integrante do grupo UPP - Rio Camaquã com o cantor gauchesco Elton Saldanha (Figura 9), numa mostra da mobilização contrária ao projeto Caçapava do Sul.

Figura 9 - Integrante do UPP-Rio Camaquã com o cantor gauchesco Elton Saldanha

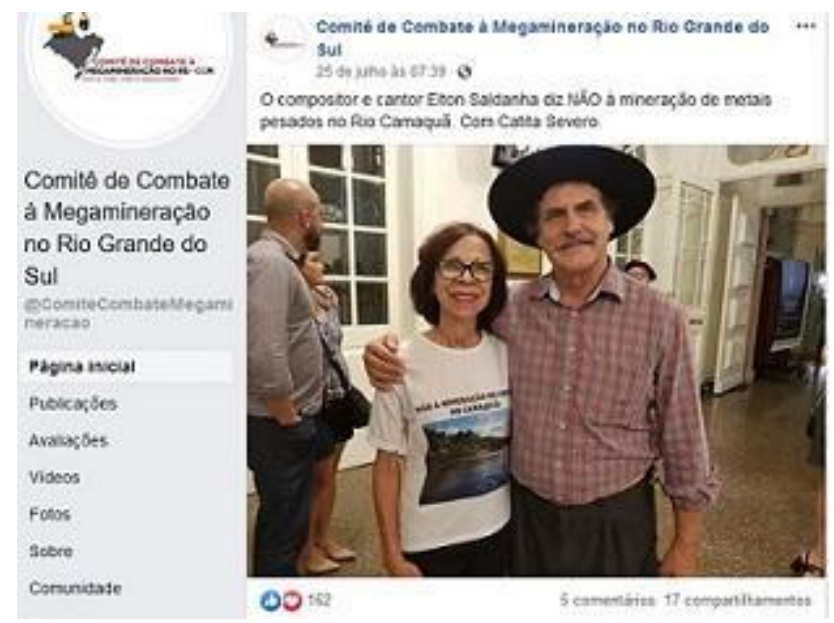

Fonte: Reprodução de Rio Camaquã - Unidos Pela Preservação

Ao analisar o papel do midiativismo ambiental no enfrentamento ao projeto de mineração no rio Camaquã, bem como os espaços que estão sendo buscados pela união de esforços contra os vários projetos de mineração no Rio Grande do Sul, entendemos, como

\footnotetext{
${ }^{22}$ Informações em: https://bit.ly/2STPL11. Acesso em: jul. 2019.

${ }^{23}$ Informações em: https://www.facebook.com/ecolavras/. Acesso em: jul. 2019.

${ }^{24}$ Informações em: https://bit.ly/2Yg2mBW. Acesso em: jul. 2019.
} 
Maciel (2012), que o desafio para o midiativismo é ir além, para "repensar seu papel enquanto mediação a serviço das lutas sociais, contribuindo, de fato, para a construção de novas relações sociais opostas às formas capitalistas de produção" (MACIEL, 2012, p. 119).

Conforme Miguel (2019, p. 190), a busca por mais democracia "depende deste enfrentamento permanente com a lógica social do capitalismo" alicerçada no ato de privatizar e concentrar riquezas, bem caracterizada pelo projeto de mineração, objeto do midiativismo ambiental sob nosso estudo. "Caso não haja outras formas de cooperação social, além daquelas orientadas para o mercado, a democracia estará condenada a ser apenas um verniz institucional para práticas que nada correspondem a seus ideais.” Em cada ação midiativista podemos ver esta vontade de mais democracia.

Pontuamos, ainda, que as postagens destacadas como exemplares indicam forte componente cultural na defesa do uso deste território. Ainda que afetados pela questão econômica e da geração de empregos, vislumbram aspectos de reconexão e integração ao ambiente, na linha da humanização do território, conforme Leroy (2014).

\section{Considerações finais}

Com o mapeamento das notícias e postagens pelos diferentes emissores (governo, imprensa e ativistas em rede social), concluímos que o governo gaúcho não dialoga com as comunidades atingidas em função de megaprojetos de desenvolvimento, bem como o jornalismo de referência (Correio do Povo) abre mão da discussão aprofundada sobre o conflito ambiental. O que resta às pessoas da comunidade é o exercício do seu livre direito à expressão, demonstrando a re-existência em favor de seu modo de vida peculiar, de seu tempo e sua lida no campo, na sua relação com o ambiente. Cabe destacar que a resistência aos projetos de mineração se dá a partir de experiências acumuladas ao longo dos anos, na luta pelo ambiente saudável e sobrevivência no território, fazendo funcionar o conceito de conflito ambiental conforme Acselrad (2005).

Também é importante salientar que as postagens dos moradores são recortes de vivências, que trazem emoção e valorização da vida, diferentemente das informações veiculadas por outros emissores que dão ênfase apenas aos investimentos econômicos. Com este estudo, reafirmamos a importância do midiativismo ambiental, ao abrir espaço para um debate livre sobre o modo de vida das comunidades. Reafirmamos, portanto, as possibilidades de visibilidade ao modo de vida herdado, porque se configuram como pontos de ruptura ao sistema hegemônico, aos quais se contrapõem; o midiativismo é aliado dos movimentos 
sociais na percepção de outras formas de organização social e das escolhas sobre o modelo de desenvolvimento, incluindo-se, ainda, a perspectiva da comunicação participativa.

Concluímos que a construção da cidadania e o direito ao ambiente saudável foram mobilizados nas postagens, trazendo a memória do modo de vida do lugar. Isso indica que há outras possibilidades de uso do rio Camaquã, desmontando, desta forma, a tese de que o desenvolvimento econômico via mineração seja o único caminho possível. Com o mapeamento, encontramos quatro principais protagonistas do midiativismo ambiental que mobiliza a luta contra o projeto Caçapava do Sul: o grupo UPP - Rio Camaquã, com duas páginas no Facebook, sendo uma da comunidade e outra do grupo público; uma página no Facebook do Comitê de Gerenciamento da Bacia Hidrográfica do Rio Camaquã e uma página no Facebook do Estuário do Rio Camaquã por A. Sig. Kath. A partir do material disseminado por estas páginas, é possível observar que o midiativismo indica seu desacordo com o projeto, baseando-se exatamente nas práticas e vivências pampianas.

Embora o midiativismo tenha sido o foco deste artigo, e ainda que as novas tecnologias possibilitem aos midiativistas alcançar formas de visibilidade, não devemos esquecer que o jornalismo tem o papel de aprofundar o pluralismo através das informações que difunde e, assim, reforçar a democracia. A relação com os meios de comunicação de massa vem se modificando com as novas tecnologias e existe reação e resistência aos poderes econômicos e políticos pelo midiativismo. No entanto, não podemos abdicar da crítica ao jornalismo de referência, pois, em acordo com Miguel (2019), não temos mais como não encarar a concentração dos meios de comunicação e do poder informativo sob a batuta de uns poucos grupos privados.

\section{Referências bibliográficas}

ACSELRAD, Henri. As práticas espaciais e o campo dos conflitos ambientais. In:

Conflitos ambientais no Brasil. Rio de Janeiro: Relume Dumará, 2005, p. 13-35.

(Org.).

Ambientalização das lutas sociais o caso do movimento de justiça ambiental. Estudos Avançados (USP), v. 24, p. 103-120, 2010.

ALMEIDA, Thiago D'angelo Ribeiro. Midiativismo e coberturas jornalísticas: mídias livres, movimentos em rede estratégias de contrapoder. 165f. Dissertação (Mestrado em Jornalismo) Centro de Comunicação, Turismo e Artes, Universidade Federal da Paraíba, 2015.

BRASIL. Constituição da República Federativa do Brasil. Brasília, DF. Disponível em: https://bit.ly/1bJYlGL. Acesso em: 22 mai. 2019.

ESCÓSSIA, Liliana da; TEDESCO, Silvia. O coletivo de forças como plano de experiência cartográfica. In: PASSOS, Eduardo; KASTRUP, Virgínia; ESCÓSSIA, Liliana da (Org.). Pistas 
do método da cartografia: pesquisa intervenção e produção de subjetividade. Porto Alegre: Sulina, 2015. p. 92-108.

GOMES, Pedro. Midiatização: um conceito, múltiplas vozes. Rev. Famecos, v. 23, n. 2. mai.-ago. 2016. Disponível em: https://bit.ly/2LQkHyS. Acesso em: 22 mai. 2019.

LEROY, Jean Pierre. Justiça Ambiental. 2014. Disponível em: https://bit.ly/2YB9Oqs. Acesso em: 22 mai. 2019.

MACIEL, Danielle Edite Ferreira. Midiativismo: entre a democratização e a assimilação capitalista. 158 f. Dissertação (Mestrado em Ciências da Comunicação) - Escola de Comunicação e Artes, Universidade de São Paulo, 2012.

MAZZARINO, Jane Marcia. O campo e a construção do capital comunicacional socioambiental. Revista de Ciências Ambientais - UnilaSalle, v. 6, n. 2, 2012.

MIGUEL, Luis Felipe. O colapso da democracia no Brasil: da constituição ao golpe de 2016. São Paulo: Fundação Rosa Luxemburgo, Expressão Popular, 2019.

MIGUEL, Luis Felipe; BIROLI, Flávia. A produção da imparcialidade: a construção do discurso universal a partir da perspectiva jornalística. RBCS [online], v. 25, n. 73, p. 59-76, jun. 2010.

MORAES, Cláudia; FANTE, Eliege. Uma cartografia do midiativismo ambiental em Porto Alegre. In: BRAIGHI, Antônio Augusto; LESSA, Cláudio; CÂMARA, Marco Túlio (Org.). Interfaces do Midiativismo: do conceito à prática. Belo Horizonte: CEFET-MG, 2018.

PASSOS, Eduardo; KASTRUP, Virgínia; ESCÓSSIA, Liliana da (Org.). Pistas do método da cartografia: pesquisa intervenção e produção de subjetividade. Porto Alegre: Sulina, 2015.

PRADO FILHO, Kleber; TETI, Marcela Montalvão. A cartografia como método para as Ciências Humanas e Sociais. Barbarói, Santa Cruz do Sul (RS), n. 38, p. 45-59, jan./jun. 2013.

SANT’ANA JÚNIOR, Horácio Antunes de; ALVES, Elio de Jesus Pantoja. Mina-ferrovia-porto: no "fim de linha", uma cidade em questão. In: ZHOURI, Andréa; OLIVEIRA, R. et al. (Org.). Mineração: violências e resistências - um campo aberto à produção de conhecimento no Brasil. Marabá, PA: Editorial iGuana; ABA, 2018.

TEISSERENC, Pierre. Ambientalização e territorialização: situando o debate no contexto da Amazônia brasileira. Antropolítica. Niterói (RJ), n. 29, p. 153-179, 2. sem. 2010.

VÉLEZ-MARTIN, Eduardo et al. Cidadania e Uso Sustentável dos Campos. In: PILLAR, Valério de Patta; LANGE, Omara. (Ed.). Os Campos do Sul. Porto Alegre: Rede Campos Sulinos UFRGS, 2015. Disponível em: https://bit.ly/1VG7u9A. Acesso em: 22 mai. 2019. p. 155-166. 